folk/ed. Derg, 2021; 27(4)-108. sayı

DOI: $10.22559 /$ folklor.1617

Araştırma makalesi/Research article

\title{
Alper Canıgüz'ün Kan ve Gül Romanı Örneğinde Çevirmen ve Dünyası ${ }^{1}$
}

\author{
The Translator and His World in Alper Canıgüz's Novel \\ Kan ve Gül (Blood and Rose)
}

\author{
Nilgin Tanış Polat* \\ Saniye Uysal Ünalan**
}

\begin{abstract}
Öz
Yapay zekâ ürünlerinin günümüzdeki tüm teknolojik gelişmelere rağmen duygusal zekâsı olan insan çevirmenlerin yerini henüz dolduramadığı çağımızda, çevirmene birey olarak atfedilen önemin de arttığını gözlemlemek mümkündür. Çevirmen figürü, farklı dillerin ve kültürlerin arasında aracılık rolü üstlenmesi bakımından günümüz dünyasında modern varoluşun bir sembolü haline gelmiştir. Çevirmen, bireyin kendini konumlandırışı ve gelişmeler karşısında duygusal zekâsıyla yaptığı başkaldırı bağlamında dünya edebiyatında karşılık bulmaktadır. Kurmaca eserlerde konu edilen çevirmen figürlerinin giderek artan bir oranda kahraman olarak kurgulandığı ve bilimsel araştırmaların bu değişimi ele almada geciktiği gözlen-
\end{abstract}

Geliş tarihi (Received): 19-01-2021 - Kabul tarihi (Accepted): 25-09-2021

* Doç.Dr, Ege Üniversitesi Edebiyat Fakültesi Almanca Mütercim ve Tercümanlık Bölümü. (Ege University Faculty of Letters, Department of German Translation and Interpretation) nilgintanis@yahoo.com. ORCID 0000-0002-6490-7395

** Doç. Dr., Ege Üniversitesi Edebiyat Fakültesi Alman Dili ve Edebiyatı Bölümü.Ege University Faculty of Letters Department of German Language and Literature suysalunalan@gmail.com. ORCID 0000-0002-4117-7158 
mektedir. Bu gözlemden yola çıkarak yazın geleneğinde izlenen bu değişimin Türk edebiyatında yankı bulup bulmadığını incelemek ve olası yeni bir geleneğin izini sürmek adına Alper Canı̈üz'ün Kan ve Gül. Bir Kara Dejavu isimli romanı bu çalışmada ele alınmış ve nitel araştırmada elde edilen veriler betimsel olarak analiz edilmiştir. Çevirmenin toplum içinde edindiği konum, gördüğü değere ilişkin araştırmalar ve çevirmenin görünürlüğü ile ilgili tartışmalar özellikle kültürel dönemeç ekseninde gerçekleşen paradigma değişikliğiyle birlikte önem kazanmıştır. Türkiye'de konuya ilişkin incelemelerin, kurmaca dünyada çevirmenlik mesleğinin toplumdaki yeri ve statüsü hakkında bilgi verse de, paradigma değişiminin izlerini sürmekte yetersiz kaldıkları saptanmıştır. Yapılan bu çalışma ile Türk edebiyatında kurmaca boyutta çevirmenin nasıl inşa edildiğine odaklanılmış, kurmaca anlatı dili ve yapısı incelenmiş, Türkiye'de çevirmene ve mesleğine ilişkin veriler 1şığında, çevirmen karakterinin modern insanı anlama yönünde bir açılım sağladığı görülmüştür. Araştırmada çeviribilimsel, edebiyatbilimsel ve kültürbilimsel açıdan esere odaklanılmış ve edebiyatta çevirmen kimliğinin bilhassa ara mekânda konumlandırılması ile beraber çevirmenlik mesleğine ilişkin yeni bir bakış açısının ortaya koyulduğu tespit edilmiştir. Böylelikle Batı literatürüne damgasını vurmuş olan kültürel dönemeç paradigması perspektifiyle Türk Edebiyatına yönelik örnek bir analiz modeli sunulmuştur.

Anahtar sözcükler: Alper Canıgüz, çevirmen figürü, kültürel dönemeç, kurmaca anlatı, kültürbilim

\begin{abstract}
In our age where artificial intelligence products cannot replace human translators with emotional intelligence despite all the technological developments, it is also possible to observe that the importance attributed to the translator as an individual is increasing. The figure of the translator has become a symbol of modern existence in today's world since it acts as an intermediary between different languages and cultures. The translator finds its response in the world literature in the context of the individual's self-positioning and rebellion against technological developments with his emotional intelligence. In this context, it can be stated that translator characters in fictional works are increasingly constructed as heroes, however academic works have registered this aspect belatedly. The aim of this study is to examine the novel Kan ve Gül. Bir Kara Dejavu of Alper Canıüz in terms of the conceptualization of the protagonist who is a translator. The main question for the analysis of this novel is whether this significant change regarding the fictional conceptualization of the translator as a hero has an echo in Turkish literature and a possible new tradition can be traced in this context. Doing this, the results obtained in our qualitative analysis are evaluated descriptively. Discussions about the translator's position in society, the value $\mathrm{s} /$ he receives, and the discussions about the translator's visibility have gained in importance with the paradigm change that takes place along the axis of the cultural turn. Studies on this topic in Turkey focus on the fictional representation of the translator and his social status, but they do not sufficiently address and trace the consequences of the aforementioned paradigm shift. With this study, the character development of the translator is focused on and the language
\end{abstract}


and structure of the fictional narrative is examined. Furthermore, in terms of the cultural knowledge related to the translator and the profession of translator, it is seen that the character of the translator paves the way for understanding modern human. The novel Kan ve Gül was analysed with reference to approaches of translation studies, literary studies and cultural studies. By this means, this study demonstrated that a new perspective on the translator profession was put forward with the positioning of the translator identity especially in the so-called third space. Thus, an exemplary analysis model for Turkish Literature is presented with the perspective of the cultural turn paradigm that has left its mark on Western literature.

Keywords: Alper Canigüz, translator figure, cultural turn, fictional narrative, cultural studies

\section{Extended summary}

In recent years we can see that the translator becomes not only the subject of fictional works such as movies and novels, but also of research in the field of translation and literary studies. This tendency can be related to the paradigm change that takes place along the axis of the cultural turn. The new approaches to identity, culture as well as to the symbolic representations of culture arising with the cultural turn make it possible, to focus on the target text instead of the source text within the context of translation studies. As a crucial component of the target text the translator itself, its definition and status as well as its basic attitudes get interesting. Parallel to the emphasis on the target text, the translator appears as an authority that conducts and determines the translation process. Moreover, in our age where artificial intelligence products cannot replace human translators with emotional intelligence despite all the technological developments, it is also possible to notice that the importance attributed to the translator as an individual is increasing. In this regard, we can say that the figure of the translator can be defined as a symbol of modern existence in today's world since it acts as an intermediary between different languages and cultures. Seen symbolically, translator figures constitute a space of circulation and interaction between texts of different cultures and worlds. They are also able to create new spaces of meaning and understanding. The translator finds its response in the world literature in the context of the individual's self-positioning and rebellion against technological developments especially with its emotional intelligence. In this context, it can be stated that translator characters in fictional works are increasingly conceived as heroes, however academic works have registered this aspect belatedly. The aim of this study is to examine the novel Kan ve Gül. Bir Kara Dejavu of Alper Canıüz in terms of the conceptualization of the protagonist who is a translator. The main question for the analysis of this novel is whether this significant change regarding the fictional conceptualization of the translator as a hero has an echo in Turkish literature and a possible new tradition can be traced in this context. Doing this, the results obtained in our qualitative analysis are evaluated descriptively.

Kan ve Gül is the fifth novel of Alper Canıüz and it can be defined as a crime novel, which contains fantastic elements. The novel tells the story of the translator Aziz who translates simple romance novels for a not particularly renowned publisher and has a rather 
monotonous life until he takes a trip into the past and thus his whole life changes. A fire breaks out during his daughter's dance performance. When he tries to save his daughter, he passes out. The novel consists of two narrative levels: On the first narrative level, the actual life of the protagonist is presented in the frame story. On the other hand, the second narrative level is about the protagonist's journey into the past. It is precisely on this narrative level that the specific importance of the translator figure can be identified. The protagonist, conceived as a translator, acts like a detective and tries to uncover certain aspects of his past. He not only changes and influences certain events, but also takes up his own life according to his individual interests after being confronted with the truth. In this context, it was found that the novel Kan ve Gül models the translator figure differently than, for example, the novel Kürk Mantolu Madonna of Sabahattin Ali. While in Ali's novel the translator Raif Efendi is characterized as a sickly, passive, helpless, calm and marginal figure, Aziz turns into a heroic figure in this novel. He manages to free himself from his monotonous existence, takes initiative and gives his life a new direction.

Discussions about the translator's position in society, the value s/he receives, and the discussions about the translator's visibility have gained in importance particularly with the cultural turn. Studies on this topic in Turkey focus on the fictional representation of the translator and his social status, but they do not sufficiently address and trace the consequences of the aforementioned paradigm shift. With this study, we not only concentrate on the character development of the translator, but also scrutinize the language and structure of the fictional narrative. Furthermore, in terms of the cultural knowledge related to the translator and the profession of translator, it is seen that the character of the translator paves the way for understanding modern human. The novel Kan ve Gül was analysed with reference to approaches of translation studies, literary studies and cultural studies. By this means, this study demonstrated that a new perspective on the translator profession was put forward with the positioning of the translator identity especially in the so-called third space. Thus, an exemplary analysis model for Turkish Literature is presented with the perspective of the cultural turn paradigm that has left its mark on Western literature.

\section{Giriş}

Son yıllarda çevirmen kimliklerinin çeşitli araştırmalara konu edildiğini ve çevirmenin bir özne olarak ele alındığını görüyoruz. ${ }^{2}$ Bu yönelim, kültür bilimlerinde kültürel dönemeç (cultural turn $)^{3}$ ekseninde gerçekleşen paradigma değişikliğiyle birlikte kültüre, kimliğe ve yazınsal metinlere yaklaşımdaki yeniliklerle ilişkilendirilebilir. Örneğin, çeviri sürecinde dokunulmaz bir ölçüt olarak ele alınan kaynak metinden ziyade 1980'li yıllardan sonra çevirmenin nasıl tanımlandığına, hangi konuma sahip olduğuna ve nasıl bir tutum sergilediğine odaklanılmaktadır. Bununla birlikte, erek metnin önem kazanması sonucunda çevirmenin kendisi de çeviri sürecini yöneten ve belirleyen önemli bir merci haline gelmektedir. " $[\mathrm{H}]$ em süreç olarak hem de ürün olarak çeviriyi anlayabilmek için öncelikle çevirmeni anlamak gerektiğini” vurgulayan Şehnaz Tahir Gürçağlar, araştırmaların yönünün çevirmenin kendisine yönelmesinin çeviribilimde "geri dönüşü olmayan bir dönüşüme" (Tahir Gürçağlar, 
2019b: 12) neden olduğunun altını çizmekte. Akademik çalışmalar, çevirmenlerin görünürlüğünün ${ }^{4}$ artmasına, çevirmene ve çeviriye verilen değer açısından olumlu yansımalara neden olmaktadır. Neumann'a göre, kültürel bilgi ve yazın, karşılıklı bir etkileşim içindedir; yazın kültürel söylemleri belirler ve kültürel söylemler de yazına etki eder (Neumann, 2006: 42). Kültürel dönemeç bağlamında da kültür ve kültürün ortaya koyduğu söylem ve ürünler arasında önemli bir yeri olan edebiyat hermeneutik ${ }^{5}$ açıdan yorumlanabilir bir obje olarak ele alınmak yerine, dâhil oldukları toplumsal ve kültürlerarası etkileşim alanları kapsamında değerlendirilmektedir (Bachmann-Medick, 2007: 45). Bu anlamda özellikle iki yaklaşıma değinmek gerekir. Clifford Geertz kültürü metin olarak düşünmekte, böylelikle gerek kültürü gerekse kültüre ait her türlü söylem ve sanatsal ürünü insan eliyle oluşturulmuş bir anlam "ağ1" olarak betimlemektedir (Geertz, 1973: 5). Stephen Greenblatt ise (kültürel) metin ile bağlam arasında sürekli var olan kültürel enerjiyi ön plana çıkararak toplum-sanat ilişkisini bir etkileşim alanı olarak görmekte ve "toplumsal enerjinin dolaşımını" (Greenblatt, 1988: 5) vurgulamaktadır. Kültür kavramının tanımlanması konusunda yeni bakış açıları sunan bu paradigma değişimin izlerini kurgusal eserlerde de tespit etmek mümkün. Bu bağlamda kurgusal olarak inşa edilen çevirmen figürlerinin de bu değişimden etkilendiği varsayımından hareketle, kültürler ve metinler arasında bir dolaşım ağı ve etkileşim alanı oluşturan çevirmen figürlerinin edebi eserlerde kahraman olarak nasıl ele alındığının incelenmesi gerektiği kanısındayız. Mesleği gereği farklı dil ve kültür dünyaları arasında gezebilen çevirmenin, alışık olunmayan, bilinmeyen ve denetlenemeyen sularda hareket etmesi, tarafsızlığından şüphe edilen ve güven telkin etmeyen biri olarak algılanmasına sebep olmaktadır. Literatürde, tercümanların kurgusal eserlerde kolektif bir metafor olarak kullanıldıkları, kültürler ve diller arasında bulundukları ara konum nedeniyle öteki olmanın zorluklarına ve kimlik sorunlarına işaret ettikleri vurgulanmaktadır (Andres, 2009: 14). Schirmer, konu edilen çevirmen figürlerinin giderek artan bir oranda kahraman olarak kurgulandığına ve bilimsel araştırmaların bu değişimi ele almada geciktiğine işaret etmektedir (Schirmer, 2014: 162). Bu çalışmada yazın eserlerinin ve filmlerin kurmaca dünyalarında bir zamanlar "dışlanan”, "yabancı", "çıkarcı" kahramanlar olarak gösterilen, ancak fiziksel veya ruhsal açıdan eksiklikleriyle göze çarpan “sessiz" çevirmenlerin ${ }^{6}$ (Kaindl, 2010: 54), günümüz eserlerinde nasıl yansıtıldığı, mesleki kimlik inşasında edebi metinlerin çevirmeni nasıl yansıttığı ve kurmaca dünyada nasıl var ettiğini somut bir örnek üzerinden göstermek amacıyla Alper Canıgüz'ün ilk baskısı 2017'de yapılmış olan Kan ve Gül. Bir Kara Dejavu isimli romanı ele alınmakta, nitel araştırmada elde edilen veriler, betimsel olarak analiz edilmektedir.

\section{1. Çevirmen figürünün ve mesleğinin kurgu açısından betimlenmesi}

Kan ve Gül, Canıgüz'ün beşinci romanıdır ve arka kapak yazısına göre "hazin, epey hareketli [ve] hayli komik" (Canıgüz, 2019) fantastik bir polisiyedir. Çok katmanlı anlam ve kurgu üzerine kurulu anlatıda ana karakter bir çevirmendir. Romanda, ucuz aşk romanları basan ikinci sınıf bir yayınevi için çalışan ve durağan bir hayat sürdüren çevirmen Aziz’in, kaderini değiştirmesinin hikâyesi anlatılmakta. Ana karakter olan Aziz, kızının dans gösterisinde bir yangının ortasında kalır ve birden zamanda yolculuk yaparak yirmi yıl öncesine döner. 
Kaderini ele geçirme farkındalığı içinde olan Aziz bu şekilde hem geçmişi hem de geleceği değiştirmeye ve böylelikle geçmişte gerçekleşen bir cinayeti önlemeye çalışır. Bu kurgunun içinde ana karakterin bir çevirmen olması ve bir dedektif edasıyla geçmişte kalan karmaşık olaylara aydınlık kazandırma çabası dikkat çekicidir. Okur, romanın sonunda Aziz'in aslında beyin sarsıntısı nedeniyle 40 gün boyunca bilinci kapalı şekilde hastanede yattığını öğrenir. Dolayısıyla romanda iki anlatım düzlemi saptamak mümkün: Birinci düzlemde kahraman figürün asıl hayatını anlatan "çerçeve hikâye" yer alırken, ikinci düzlemde zaman yolculuğunun gerçekleştiği ve ilginç olayların meydana geldiği "iç hikâye" yer almaktadır. Anlatılan hikâye işte bu ikinci düzlemde kahraman figürün gördüğü rüyanın aktarımına dayalıdır. Çalışmamızın devamında romanın ana karakteri olan Aziz analiz edilmekte, karakterin çevirmen olarak ne şekilde yansıtıldığı gösterilmekte, bunun yanı sıra anlatım kuramı açısından bakıldığında ben anlatıcı olarak kurgulanmasının işlevleri üzerinde durulmaktadır.

Kurgusal eserlerde çevirmenlerin nasıl yansıtıldığını gösteren bilimsel yayınlar ${ }^{8}$ arasında özellikle Kaindl'ın analiz yöntemi (Kaindl, 2008) ${ }^{9}$, çevirmenin incelenmesine kolaylık tanıyan önemli bir yaklaşım sunar. Bourdieu'nün habitus (Bourdieu, 1984) kavramına dayanan Kaindl'a göre çevirmen rolü, üç ölçüt üzerinden incelenebilir. İlk ölçüt çevirmenin fiziksel betimlemesine, ikinci ölçüt ruhsal betimlemesine, üçüncü ölçüt de çeviri uygulamalarına yönelik sunulan betimlemelere odaklanmayı ön görür (Kaindl, 2008: 311). Çevirmen Aziz’in fiziksel betimlemesi ile ilgili sunulan bilgiler sınırlıdır. Aziz geçmişe döndüğünde aynadaki yansımasına şaşırmaktadır. İleri yaşlarda sahip olacağı fazla kilolardan, saçına ve sakalına düşen aklardan ve yüzündeki kırışıklıklardan kurtulmuştur. Kendisini öncekine kıyasla "yakışıklı" ve "müthiş” bulmaktadır (Canıgüz, 2019: 54). Geçmişe döndüğünde silinen kusurları ruhsal açıdan da bir değişime ve hayata daha olumlu yaklaşmasına yol açar. Aşağıda yer alan cümleler bu değişimi ve beklentilerini gözler önüne sermektedir:

\footnotetext{
"Gençtim, güzeldim, sağlıklıydım. Çayımdan, sigaramdan en son ne zaman bu kadar keyif aldığımı hatırlamıyordum bile. Kendimi kuş gibi hafif hissediyordum. Bir an önce yeni hayatımı yaşamaya başlamak için sabırsızlanıyordum. Üzümünü yemek çağını sormamak istiyordum (a.g.e, 54-55).

İkinci bir şansa kavuşmuştum ben! Her şeyi düzeltebilir, yepyeni ve güzel bir hayat kurabilirdim kendime. İyi bir insan olabilirdim (a.g.e, 57).

[K]aderim, bu kez en güzel mısralarla yazılmak üzere bir kez daha kendi ellerimdeydi” (a.g.e, 59).
}

Canıgüz’ün ikilemler üzerine kurulu anlatısında, Aziz “[h]oşgörülü ama eleştirel, girişken ama saygıllı, açık fikirli ama korkak, güler yüzlü ama umutsuz” birisidir (a.g.e, 30). Her ne kadar eski eşinin gözünde "en büyük yeteneği [...] sorunları görmezden gelme[si]" olsa da aslında kendisini "çözümcül bir insan” olarak tanımlamaktadır (a.g.e, 30). Eline geçen firsatla birlikte boşandığı eşi Nergis’e halâ ilk günkü aşkla bağlı, "patolojik döngü” (a.g.e, 12) içinde şimdiki ve geçmiş zamana saplanmış "hapishaneye dönüşmüş" (a.g.e, 9) hayatından kurtulma ümidiyle dolmuştur. Meslek hayatına mütercim-tercümanlık öğrencisiyken iken cep harçlığını çıkarmak amacıyla Paradise Yayınevi'ne adım atmış ancak geçen yıllarla birlikte geçici bir iş yeri olarak gördüğü bu yayınevine bağlı kalmıştır. "[B]oktan aşk roman- 
ları" çevirmekten ve yayınevindeki statüsünün bu süreç içinde hep aynı kalmasından dolayı son derece mutsuzdur (a.g.e, 15). İşi maddi açıdan tatmin etse de manevi olarak olumsuz duygular içindedir:

"Zaman zaman, çalışma odamın duvarında posteri asılı duran Shakespeare'in eleştirel, hatta tiksinti yüklü bakışları altında, onca eğitimi bu âdi uğraş için mi aldığım türünden sorular yüreğimi daraltıyor idiyse de, [...] dolgun çek elime geçtiğinde, hissettiğim vicdan azabı yatışıp yitiveriyordu" [...] (a.g.e., 15).

Her ne kadar mesleği ile ilgili yaptığı çalışmalar Aziz'i tatmin etmese de, onun maddi beklentilerini karşılar niteliktedir. İşiyle ilgili yaşadığı ikilem, çeviri uygulamalarında da kendini gösterir. "Çeviri aslına sadık mı serbest mi olmalıdır?” sorusuna yirmi yıldır bir yanıt bulamadığı anlaşılmaktadır (a.g.e., 30). Bir “aşk romanları çevirmeni” olmasına rağmen bu türe özgü sevişme sahnelerini çevirememektedir. Örneğin bir sayfayı en fazla on dakikada çevirirken, sevişme sahnelerini çevirmek için saatlerce uğraşmakta veya Nergis'e çevirtmektedir (a.g.e., 154).

İkilemler içindeki Aziz için geçmişe giden ve "düğümlenmiş hayatını yola koyabilmek için düğümden başlayıp oradan çözmeye" (Çeşit/ Kozanoğlu, 2017) başlayacağı geçit, bir kuru temizleme dükkânıyla açılır. ${ }^{10}$ Sahibi İskender Doğan, Kan ve Gül şarkısıyla şöhreti yakalayıp sonra başka eser ortaya koymamış bir sanatçıdır. İlk karşılaşma anında H. G. Wells'in Zaman Makinesi adlı romanını okuyan İskender Doğan'la aralarında geçen konuşma dikkat çekicidir:

"Çevirmenim ben," dedim. "Sait Faik'in eserlerini İngilizce'ye kazandırmaya çalış1yorum.” Yalan sayılmazdı aslında, neticede nihai amacım buydu ve İskender Bey'in ne bileyim, öyle kullanım kılavuzları, broşürler falan çevirdiğimi düşünmesini istemiyordum.

“Öyleyse beni anlayacaksınız,” dedi dostça gülümseyerek. "Siz de sanatçı sayılırsınız." "Yok canım, o kadar da değil..."

"Bakın çeviri yaparken kimi zaman en doğru anlatım biçimini, hatta mükemmel sözcügü bulmak için inim inim inlediğiniz olur, değil mi?

Orijinalinde hayli sert geçen seks sahnelerini yerli okuru rahatsız etmeyecek ama hayal gücünü de büsbütün öldürmeyecek biçimde uyarlamak, aşağı yukarı aynı anlama gelen yirmi İngilizce sıfatı tekrara düşmeden kullanmaya çalışmak ya da hedef kitlemizin poker oyununu bilemeyecekleri varsayımıyla bir strip-pişti sahnesi yazmaya kasmak... Herhalde onun kast ettiği böyle şeyler değildi ama benim uğraştığım içerik de buydu işte, ne yapayım? "Elbette," diye onayladım (a.g.e., 27-28).

Aziz, "Hem iyi bir sanatçı, hem de tevazu sahibi” (a.g.e., 26) İskender Doğan’a kendini ve mesleğini tanıtırken çevirmen kimliğine dikkat çekip kendini beğendirme çabasına girmektedir. Bu nedenle popüler romanlar yerine sanatsal niteliği aşikâr olan yüksek edebiyatın seçkin yazarlarından Sait Faik’i çevirdiğini söyler. Nitekim çevirmenlerin statüsü açısından belirleyici bir etmendir bu farkl111k: 


\begin{abstract}
“'Saygın edebiyat' alanında etkinlik gösteren çevirmenler popüler edebiyat alanında çeviri yapan meslektaşlarına göre her zaman daha görünür kılınmakta ve yüksek bir konumda algılanmaktadır. Popüler edebiyat alanında çalışan çevirmenler ise genellikle 'isimsiz' ve sessiz bir grup olarak var olmakta ve edebiyat gündeminde kendilerine bir yer bulamamaktadır” (Tahir Gürçağlar, 2015: 89).
\end{abstract}

Tahir Gürçağlar, popüler edebiyatı, Bourdieu’nün “büyük ölçekli üretim alanı” tanımından yola çıkarak, "ticari ya da siyasi kazançla yönlendiren ve eleştirmenlerin ve tarihçilerin büyük ölçüde değersiz saydığı bir alan" olarak tarif ederken bu alanda üreten yazarların ve çevirmenlerin gelecekte unutulmaya mahkûm olduklarını belirtmektedir (Tahir Gürçağlar, 2015: 89). Bu bağlamda, Aziz'in bir otorite olarak gördüğü İskender Doğan'ın kendisi hakkında yazın çevirisi ${ }^{11}$ yaptığını, kullanım kılavuzları, broşürler vb. teknik çevirmediğini düşünmesini istemesi önemlidir. Yaptığı işin onun tarafından takdir edildiğini görmek, onun gözünde de bir sanatçı olmak hoşuna gider, çünkü “İskender Bey sanatçı değildir; o sanatın ta kendisidir" (a.g.e., 132) ve onun tarafından kabul edilmek, onay görmek ve beğenilmek Aziz için son derece önemlidir. Bir mesleğin imajı, kuşkusuz toplumun değer yargılarına bağlı olarak değişim göstermektedir. Ancak romanda, insanın kendi mesleğine karşı izlediği bireysel tutuma da vurgu yapılmaktadır; nitekim İskender Bey, Aziz ile olan konuşmasında şöyle demektedir: "Müşteri memnuniyeti çok önemlidir bizim için [...] [m]esleğe saygı, daha da önemlidir" (a.g.e., 135). Bir insanın mesleğine karşı gösterdiği özen ve işini yaparken izlediği tutum, onun kişiliği ile ilgili de bilgi vermektedir. İskender Bey'in tavrı bu açıdan dikkat çekicidir ve mesleği konusunda dengesiz bir tavır gösteren Aziz için cesaretlendiricidir.

\title{
2. Arafta olan çevirmen
}

Eserlerinde canlandırdığı sıra dışı karakterlerle okurlarını şaşırtmayı seven Canıgüz, Kan ve Gül üzerine yaptığı bir söyleşide yarattığı kurgularla ilgili şöyle demektedir:

"Karakter oluşturmak benim en hassasiyetle üstünde durduğum konulardan biri ve hayli çetrefilli bir iş. Çok genel hatlarıyla şöyle söyleyebilirim belki, bir karakter, onun karakter olduğuna inanmamızı sağlayan özelliklerini en beklenmedik taraflarından alıyor. Tip dediğiniz, üç aşağı beş yukarı öngörülebilir, kaba bir tanımlamadan ibaretken onu karakter haline getiren şey, dünyayla başa çıkarken geliştirdiği kendine özgü yöntemler, düşünüş biçimleri ve hatta patolojileri. Herhalde bir tek yolu yoktur ama benim bu meseleyle uğraşma biçimim belki "mayalama" diye özetlenebilir; tanıdığım, bildiğim, üstünde düşündüğüm birine kendimden, kendime de o kişiden bir maya çalmak şeklinde" (Pekdoğan, 2017).

Hayatının bir döneminde çeşitli yayınevlerinde çevirmenlik de yapmış olması, Canıgüz'ün otobiyografik unsurlardan beslenmiş olduğuna işaret etmektedir. Nitekim yazar, konuyla ilgili yöneltilen soruya, "[romanın] [k]aba hatlarıyla otobiyografik bazı unsurlar taşıdığı söylenebilir ancak bu bire bir değil, daha ziyade bir mekân tasarlarken, iyi bildiğin bir yeri hayal etmek gibi düşünülebilir", yanıtını vermiştir (Menteş, 2017). Çevirmenlik yapan ana karakterin ben anlatıcısı ile kurgulanmış olması önemlidir. Çünkü anlatının ikinci düzleminde yer alan ve iç hikâyeyi oluşturan rüya ile birlikte zaman boyutunda geçmişe 
gidilmektedir. Bu zaman yolculuğu aracılığıyla metnin zamansal kurgusunda bir "anakroni" (bkz. Scheffel/ Martinez, 2020: 42) meydana gelmekte ve "anlatıcı" ikiye bölünmektedir: "Yaşayan ben" ve "anlatan ben" (Scheffel/ Martinez, 2020: 86). Dolayısıyla, okur, anlat1lan dünyayı tamamıyla ben anlatıcısının gözünden görmekte ve onun yorumlarıyla algılamaktadır. Böylece, anlatım kurgusu içinde çevirmen figürü tam bir başkahramana dönüşür. "Güçlü, değerli ve şerefli” anlamlarını taşıyan “Aziz” (Harman, 1991) ismine yaraşır şekilde bir dönüşüme uğrar. Bu bağlamda romanın polisiye olarak tasarlanmış olması da önemlidir. Zira polisiye türünün ${ }^{12}$ kalıplaşmış özelliklerini fantastik unsurlarla birleştirmesi bakımından Kan ve Gül, polisiye türüne yeni bir soluk getirmektedir. Yazar, bu "türün temel özelliklerini” koruduğunu, ama "ona özgün bir nitelik de katmaya” çalıştığının altını çizmekte, eserin "suç ve çözüm arasındaki zamansal ilişkiyi tersine” çevirdiğini belirtmektedir: "İşlenmemiş bir suçun failini bulmak... Alışılageldik polisiyelerdekinin tersine, geçmişin geleceği değil, geleceğin geçmişi belirlediği bir hikâyedir" (Menteş, 2017). Bu çerçevede gelişen anlatıda "Çevirmen Aziz"in görünmez olan aracı kimliğini değiştirerek görülebilir olmasıyla, hatta bunun da ötesinde gören ve olayları çözümlemeye çalışan durumuna gelmesiyle beraber, “Araf”taki kahraman"a dönüşmektedir.

Romanda incelenmesi gereken bir başka karakter de Abdül'dür. Her ne kadar eski tiyatro grubundan arkadaşları onu tanısa da, Aziz ancak geçmişe yolculuk yaptığında öldürüldüğü söylenen Abdül ile tanışır: "Yay gibi gergin incecik bir beden, hafiften çekik gözlerinde zekâ pırıltıları, dudağında alaycı, hatta küstah bir gülümseme” (a.g.e., 72). Gelecekte neler olacağının bilinciyle geçmişi sürekli olarak değerlendiren ve bir şeyleri değiştirmek isteyen Aziz, Abdül'ün ölümünden kendisinin sorumlu olabileceği korkusunu yaşar ve Abdül cinayetinin failini bulmak için harekete geçer. Suç ve çözüm arasındaki zamansal ilişkinin tersine çevrilmiş olmasının yanı sıra, polisiye türü için belirleyici olan suç ve çözümleme olguları da romanda farklı bir şekilde karşımıza çıkmaktadır. Çevirmen olan ana karakter hem dedektif işlevi görmektedir, hem de geçirdiği gerçeküstü zaman yolculuğu içerisinde gerek kurgusal düzlemde gerekse romanın anlatımı açısından önemli bir üst bakışa ve hâkimiyete sahiptir. Böylelikle romanda üstkurmaca anlatıma özgü unsurlar da ortaya çıkmaktadır. Romanın henüz ilk cümlelerine bakıldığında ana karakterin bu anlatı ve kurgu içindeki anahtar konumu anlaşılmaktadır:

\footnotetext{
"Gelecek, bazıları için, hakikaten de uzak bir hatıradan ibarettir. Böyleleri açısından varoluş, hayatın meşum bir noktasında, şimdiki zamandan ileriye doğru uzanan bir yol olmaktan çıkıp, onları geçmişle gelecek arasında sıkıştıran bir hapishaneye dönüşmüştür. $\mathrm{Bu}$, trajik bir hal midir? Herhalde öyledir. Fakat burada bize düşen, kimseyi yargılamak değil; bir köle, ama muhakkak ki pek isyankâr bir köle saymak gereken insanın hazin kaderine dair bir hikâye anlatmak. O yüzden, gelin, az önce sözünü ettiğim iflah olmaz türün bir mensubu sıfatıyla, size her şeyi ta en ortasından başlayarak anlatayım” (a.g.e., 9).
}

Ben anlatıcısı olan ana karakter burada okura seslenmektedir. Varoluşu bir "sıkışmışlık hali" olarak betimleyen Aziz bu trajik duruma bir son verebilecektir. Nitekim romanın ilk cümlelerinde hakikat, varoluş, kader gibi kavramlar öne çıkmakta, bu da romanın bütünü göz önünde bulundurulduğunda en genel anlamda modern insanın sorunlarına temas edildiğini göstermektedir. 
Aziz geçmişe gittiği ilk anlarda yazarlık çalışmaları bulunan bir öğrenciyle tanışır. Romanını tanıtırken dile getirdiği özellikler, kuşkusuz Kan ve Gül eseri için de geçerlidir: "Hem modern, hem klasik, [...] Hem gerçekçi, hem gerçeküstücü. Hem komik, hem duygusal. Hem polisiye, hem değil...” Esasında "psikolojik arazları" ve "geçmişe dair saplantıları" olan Aziz ideallerini gerçekleştirememiş bir "kaybedendir" (Menteş, 2017). Ancak kurgu içinde ona verilen çözümleyici rol bakımından âdeta bir kahramana dönüştügü söylenebilir. Dolayısıyla Kan ve Gül romanı sadece polisiye türüne değil, aynı zamanda çevirmen figürünün kurgusal olarak inşa edilmesine de yeni bir soluk getirmektedir.

Yukarıdaki alıntıda işaret edildiği gibi Aziz'in her şeyi en baştan değil de, "en ortasından" anlatacak olması ele alınması gereken diğer bir unsurdur. Zira bu figürün geçmişe doğru yaptığ1 zaman yolculuğu, onun "hayat kurgusunun" ve hayatındaki tüm anlamların "alt üst oluş süreci” (Menteş, 2017) olarak karşımıza çıkmaktadır. Anlatım kuramı açısından bakıldığında romanda "intradiegetik-homodiegetik", yani "kendi hikâyesini anlatan ikinci basamak anlatıcısı" (Scheffel/ Martinez, 2020: 95) söz konusu, bununla birlikte "anlatan" ve "yaşayan” bir ben’e bölünmüş olan anlatıcının farklı iki zamansal ve mekânsal alanın ortasında veya arasında konumlandırılması sonucunda bir bakıma yeni bir ara mekân kurgulanmaktadır ki, buna "üçüncü alan" demek mümkün. Esasen postkolonyal kuram kapsamında irdelenen bu kavramı kültürbilimsel açıdan ele alarak daha kapsamlı bir bakış açısı sunan Bachmann-Medick’e göre “üçüncü alan”'13, kültürel çevirinin ve kültürlerarası iletişimin gerçekleşmesine zemin oluşturmaktadır:

\footnotetext{
"Was aber bedeutet das Konzept eines „dritten Raumes“ für die Situation des Kulturenkontakts und für die Orientierung innerhalb der eigenen Kultur selbst? „Dritter Raum“ ist ein Medium sozialer Interaktion, das Kommunikationsformen wie Übersetzen und Aushandeln von Identitätsunterschieden in den Vordergrund rückt.

Peki "üçüncü alan" kuramı, kültürlerin teması ve öz kültür içindeki yönelim bakımından ne anlama gelmektedir? "Üçüncü alan”, kimlik farklılıkları çevirme ve müzakere etme gibi iletişim şekillerini ön plana çıkaran toplumsal bir etkileşim aracıdır” (Bachmann-Medick, 1999: 522). ${ }^{14}$
}

Mutlak kabul edilen her türlü anlamın tersyüz edildiği üçüncü alanda, yüzleşme, müzakere etme ve yeniden anlamlandırma gibi süreçler önem kazanmaktadır (Bachmann-Medick, 1999: 521-522). Canıgüz'ün romanında çevirmen olan Aziz, içinde bulunduğu gerçeküstü zamansal yolculuğunda geçmişi ve geleceği ile yüzleşmekte, hayatındaki anlam ifade eden gerçekleri müzakere etmekte ve bunları yeniden anlamlandırmayı başarmaktadır. Çevirmen olan ana karakterin yaptığı sıra dışı zaman yolculuğu ve arafta bulunma durumu Bachmann-Medick'in bakış açısıyla değerlendirildiğine, anlatan ve yaşayan ben olan Aziz'in geçmiş ve geleceğe dair bilgisinin birbiriyle temasa geçmesi sonucunda sürekli olarak olay ve kişileri yeniden anlamlandırmaya ve çözümlemeye çalıştığını gösterir. Bu durum, yapısal olarak bakıldığında çevirmenin çeviri sürecindeki konumuyla da ilişkilendirilebilir, çünkü kaynak metinle erek metin arasında bir eşdeğerlilik arayışında bulunan çevirmen de benzer şekilde bağlamdan yararlanarak bir anlamlandırma çabasındadır. Çevirmenin kimliği üzerinden yapılan tartışmaların önemini vurgulayan Bahadır, çevirmenin "ara konumuna” ilişkin şöyle demektedir: 
"Çevirmen, [...] iletişim anında kesin çizgilerle belirlenmiş kimlikleri bozar, iki tarafı da hem temsil eder hem de temsil etme olgusu tamamen yikarak kendisi bir üçüncü taraf oluşturur ve iletişime etken ya da edilgen bir biçimde katılır. Mesleki kimliği olsun toplumsal kültürel kimliği olsun, yaptığı iş nedeniyle, bulunduğu 'ara' konumda çevirmen de bir 'ara kültür' oluşturur. [...] [Ç] evirmenin bu ara konumunu yeniden gözden geçirmek, olumlu yönlerini açığa çıkarmak ve şimdiye dek 'zor', 'karışık', 'bulanık', 'elle tutulmaz' olarak tanımlanan bu durumda yeni potansiyeller arayabiliriz. [...] Böyle bir adım, çevirmenin 'özel' konum ve kimliğinden yola çıkarak başka kimliklerin de sorgulanmasını beraberinde getirir” (Bahadır, 2004: 28).

Kızının gösterisine gittiğinde kendisini ne kadar "yabanc1" (a.g.e., 34) hissettiğini vurgulayan Aziz, hayatındaki mutlak sandığı anlamlara veda edecektir. Kendisini kaza sonrası aniden farklı bir alanda ve zamanda, âdeta arafta bulur:

"Yattığım yerde gözlerimi aralıyorum. Devasa karanlığın içinde ufak tefek beyaz benekler. Havada hafif bir serinlik. Elimin altında sslak çimenler. Ciğerlerim açık, vücudum dinç. Cennet? Kısa bir muhasebe yapıyorum; mümkün değil. Öte yandan cehennemde olduğumu düşündürecek bir emare de yok ortamda. [...] Kabir azabı bu içinden çıkılmaz sorularla mı başlamaktaydı? Benim gibi, her zaman akılcı düşünceyi kendine rehber edinmiş biri için biraz utanç verici belki ama yapacak bir şey yok;” [...] (a.g.e., 45-46).

Bulunduğu zamansal ve mekânsal alan, Aziz'e göre bir "rüya", "koma”, "paralel evren" veya “alacakaranlık kuşağı” (a.g.e., 51) ile benzerlik göstermekte. Durumunun nedenselliğine yönelik herhangi bir rasyonel açılama yapamayan Aziz, netice itibariyle şu saptamada bulunur: "1994 yılına dönmüştüm” (a.g.e., 51). Bunu ikinci bir şans olarak gören Aziz, her şeyi düzeltebileceğini, "yepyeni ve güzel bir hayat" kurabileceğine ve "iyi bir insan" olabileceğine inanmaktadır (a.g.e., 57).

Geçmişine döndüğünde Aziz’i en çok eski eşi Nergis'in ona verdiği duygular heyecanlandırır. Ancak Nergis'in davranışları ve söyledikleri onun içinde büyük kuşku uyandırır. Hatta Nergis ile Abdül arasında bir ilişkiden şüphelenmektedir. Başlangıçta hissettiği güzel duygular kaybolmuştur: "Saçmalıyordum. Geçmiş ve gelecek hakkındaki bütün inançlarım alt üst olmuştu” (a.g.e., 104). Giriştiği anlama ve çözümleme yolculuğunda İskender Doğan ile yaptığı konuşma bu bağlamda önemlidir:

“İnsanlar hayatlarını hep bir cevap arayarak geçirirler,” dedi İskender Doğan. "Oysa çoğunun sorunun ne olduğu konusunda hiçbir fikri yoktur."

"Katil olmaktan korkuyorum," deyiverdim birden. "Gelecekte... ya da rüyamda, bu Abdül denen herifin öleceğini görmüştüm. Bunu bana anlatan kişi, onun bir cinayete kurban gittiğini söylemişti. Şimdi acaba onun katili ben miyim diye merak ediyorum." "Fakat henüz kimseyi öldürmediniz, değil mi?"

"Hayır ama ya öldürürsem?"

"O zaman katilin kim olduğunu öğrenmiş olursunuz," dedi İskender Doğan ve sonra da dünyanın en tuhaf sorusunu sordu: "Peki, ya öldürmezseniz?"

“Anlayamadım," dedim rakımdan bir yudum alıp.

"O zaman katilin kim olduğunu öğrenemezsiniz." 
$[\ldots]$

İskender Doğan bana döndü, elini omuzuma koyup gözlerini benimkilere dikti. "Kanı takip et, evlat," dedi. "Gülü orada bulacaksın" (a.g.e., 136-137).

Aziz, yaşadığı bu kargaşada “[n]eler döndüğünü anlayabilmek için, Abdül'ün ölümünün ardındaki esrarı aydınlatma[s1]” (a.g.e., 139) gerektiği düşüncesindedir. Geçmişine yolculuk yapan, geçmiş ile gelecek hakkında bilgi sahibi olan Aziz, çeviri sürecinde bulunan bir çevirmen gibi, karakterlerin başına neler geleceği bilgisine, yani bütüncül ve hâkim bir bakış açısına sahiptir. Çevirmen, çeviri sürecinde kaynak metne bütüncül bir bakış açısıyla yaklaşır. Karakterlerle ilgili verilen tüm bilgiler ışığında ve olay örgüsünün zamansal bütünlügü içerisinde metnin bağlamında kalarak çevirisini yapar. Bu anlamda kaynak metne hâkimdir. Buradaki ben anlatıcısı yapmış olduğu zamansal yolculuk kapsamında çevirmenin bu bilgeliğine eşdeğer bir bakış açısına sahiptir. Benzer şekilde Aziz de "hakim" konumu sayesinde Abdül cinayetini engellemeye çalışır, ancak olacakları engelleme konusunda yetersiz kalır, çünkü Bassnett'in Translation as Re-Membering isimli makalesinde yazdığı gibi, kusursuz bir iş, kusursuz bir işleyiş yoktur:

[...] çeviri her zaman büyük önem taşımaktadır, çünkü çeviri yoluyla geçmiş geleceğe aktarılır. Çeviri, tıpkı bellek gibi her zaman güvenilmezdir, çünkü kusursuz bir bellek veya kusursuz bir çeviri olamaz. Ancak çeviri, tıpkı bellek gibi, geleceği yazar ve bunu geçmişi yeniden yazarak yapar.

[...] "translation is always of immense importance, for through translation the past is handed on to the future. Translation, like memory is always unfaithful, because no absolutely perfect memory or absolutely perfect translation can exist. But translation, like memory, writes the future, and it does so through re-writing the past" (Bassnett, 2003: 308-309).

Aziz de bu çerçevede “mükemmel” bir sonuca ulaşamaz, fakat Abdül’ün Aziz’e söylediği sözler, Aziz'in üçüncü alan olarak tanımladığımız bu yolculuğunda hayatı yeniden anlamlandırma sürecine aydınlık katar niteliktedir. Abdül etrafındaki insanların yaşam tarzlarını katı bir şekilde eleştirmekte ve yaşadıkları hayatın bir yanılsama olduğuna işaret etmektedir (a.g.e., 165-166). Aziz’e ise doğrudan şu sözlerle hitap edip onu âdeta uyandırmak ister: "Sana tavsiyem, bildiğini zannettiğin şeyleri yeniden gözden geçirmen. Çok fazla düşünüyorsun ama basit düşünmeyi başaramıyorsun" (a.g.e., 166). Nihayetinde cinayeti engelleyemeyen Aziz, Abdül'ün evine gittiğinde yerde bulduğu ölü bedeni kendisine doğru çevirir ve böylece kendi yüzüyle karşılaşır (a.g.e., 199).

Psikanalitik açıdan bakıldığında Abdül karakterinin Aziz'in bir yansıması olduğu söylenebilir. Bu anlamda komadan gerçek hayata uyanan Aziz, "bu adamın ne kadarı yaşarken olduğu kişi, ne kadarı parçalanmış ego[sunun] bir yansıması" (a.g.e., 203) olduğu konusunda düşünmektedir. Gerçeküstü olan ve rüyada geçen bu deneyimler sayesinde Aziz "geleceği değil, geçmişi görebilme" olanağını yakalar ve önemli bir bilinçlenme yaşar: "Belki de, hayatın kontrolsüz bir düşüş olduğunu kabul edip ona mutlu bir son aramak yerine, iyi bir hikâye olmasına gayret etmeliydim,” (a.g.e., 90) der. Geçmişine ve yaşadığı zamana dair 
düğümleri çözümleyebilen Aziz, eski eşinin geçmişte gerçekleşen bu cinayetin faili olduğunu artık bilmektedir. Romanda çevirmen olan ana karakterin böyle bir çözümleme sürecinin kahramanı olmasına ilişkin Canıgüz de Aziz'in yaşadığı çözülmenin "kritik” olduğunun altını çizmektedir (Menteş, 2017). Bu çerçevede, kitap kapağında görülen adamın "sökülen bir örgü-adam" (Menteş, 2017) olarak resmedilmesi, tüm geçmişini ve hayatını çözen, yani söküp tekrar ören Aziz olduğu şeklinde yorumlanabilir. Çalışmamızda "üçüncü alan” olarak değerlendirdiğimiz yolculuğunda Aziz'in güçlenen çevirmen kimliğini belirgin bir şekilde görmekteyiz. Aziz'in bir yandan çeviri sürecinin kontrolünü ele alması ve çevireceği eserin seçimini yaparak söz sahibi olması, diğer yandan başka yeteneklerini keşfetmesi bunun apaçık bir göstergesidir:

"Gerçek ya da değil, "alternatif geçmişimde" yaşadıklarım, hayatımı önemli ölçüde değiştirmişti. Öncelikle daha bir çekidüzen vermiştim kendime. Eskisi kadar içmiyor, televizyon karşısında vakit öldürmüyordum ve inceden Sait Faik çevirilerine bile girişmiştim. En önemlisi, Paradise Yayınevi'ni bırakıp, küçük bir reklam ajansında düzeltmenliğe başlamıştım. Memnundum işimden. Reklamcılığa yeteneğim olduğu ortaya çıkmıştı ve ara sıra yaratıcı grup toplantılarına dahi katılmaya başlamıştım” (a.g.e., 204).

Romanın kapak resmini de belirleyen "çözümleme" ve "sökülen örgü” metaforları bu bağlamda çok anlamlıdır. Zira bir çevirmenin yaşam ve deneyimlerini anlatan Canıgüz'ün bu romanı, insan hayatını bir metin olarak kurgulamaktadır. Romanın bu kurgulama şekli Geertz'in kültür tanımını hatırlatmaktadır. Geertz'e göre insan kendisinin ördüğü anlam ağlarında asılı duran bir "hayvan", kültür ise bir "ağdır". Bu nedenle kültürün analizini, düzen arayışında deneysel bir bilim olarak değil de, aksine "anlam” arayışında yorumlayıcı bir bilim olarak görmektedir (Geertz, 1973: 5).

Buradan da anlaşılabileceği gibi, insan kendisi tarafından örülen anlam ağları içerisinde hareket etmektedir. Kültür içerisinde yer alan anlamların böyle bir ağ olarak görülmesi, kültürü de bir ağ olarak tanımlamaya olanak sağlamaktadır. Nitekim bir çevirmen de farklı bir kültüre ait olan bir metni erek kültürün diline çevirirken ilgili metindeki tüm kültürel anlam ağlarını çözümlemeye çalışmakta ve sürekli olarak üçüncü alan için karakteristik olan yüzleşme, etkileşim, müzakere etme ve yeniden anlamlandırma çabasına girmektedir. $\mathrm{Bu}$ çerçeveden hareketle, romanın çevirmen kurgusunda aslında bu tablonun daha geniş versiyonunu gördüğümüzü söylemek mümkün, çünkü Aziz iki zaman arasında kalarak kendi hayatını çözümlemekte ve yeniden anlamlandırmaktadır.

\section{Tartışma ve sonuç}

Özellikle pandemi ile birlikte sanal mekânların gerçek mekânların yerini alamaması, modernite anlayışının ters yüz edilmesi, bireyin konumu ve bireyin toplumla ilişkisi, sosyolojik anlamda birçok değerin ve değişmez kabul edilen anlam bütünlüklerinin değişimini beraberinde getirmiştir. Değişen değerlerle birlikte bireyi anlamak ve yorumlamak hiç bu kadar önemli olmamıştır. Çünkü bilimde ve teknolojide gelişmelerin baş döndürücü bir hızda ilerlediği günümüzde, insan verimliliği ölçüsünde değerlendirilirken modern birey kendini 
yalnızlık, umutsuzluk, yabancılaşma gibi duygular içerisinde bulmuştur. Modern zamanların anlatım türü olan ve modern çağ insanının yalnızlığından doğan roman, insan doğasına ve insan-toplum ilişkisine yönelik değerlendirmeler ve bakış açıları sunan önemli bir edebî türdür. Bilim ve teknoloji pek çok sorunu çözerken, birçok sorunu da beraberinde getirmiş, öngörülemeyen sonuçlar doğurmuştur. Bu bağlamda, temelinde "insanı anlama" yönünde edebî eserler üzerinden yapılan araştırmalardan elde edilecek veriler, oluşan ve oluşacak olan sorunların üstesinden gelmeyi de kolaylaştıracaktır. Ne de olsa "gerçek metinler" olan ve "gerçek bir yazar" tarafından kaleme alınan edebî/ kurmaca metinler, "gerçek bir okuyucuya" seslenmeleri bakımından "gerçek iletişimin bir parçasıdır" (Scheffel/ Martinez, 2020: 24). Bu gerçek iletişimin parçası olan edebî metinlerin ve tüm kurgu eserlerin çevirmenleri de bu iletişim ağında yer alan gerçek ve önemli unsurlardandır.

Bulunduğumuz iletişim çağında çeviriye verilen önemi, geliştirilen çeviri yazılımları ve makine çevirilerine yapılan yatırımlar üzerinden izlemek olasıdır. Ancak bu gelişmelerle birlikte birey olarak çevirmene atfedilen önemin de arttı̆̆ını gözlemlemek mümkün. Bu bağlamda, çevirmenin görünürlüğü ile ilgili tartışmalar ve özellikle son yıllarda bilimsel araştırmalarda çevirmenin birey olarak incelendiği çalışmalar önemli birer göstergedir.

Çevirmenlik mesleğinin nasıl algılandığını inceleyen Nuran Aslan, 2000'li yılların başında gelişmiş ülkelerde yazınsal metinlerin çevirmenlerine maddi ve manevi değer verilirken Türkiye'de çevirinin bir yan uğraşı olarak entelektüellerin ve akademisyenlerin yer aldığı küçük bir azınlık tarafından sürdürüldüğünü ve çevirmenliğin meslek olarak kabul edilmediğini belirtmiştir (Aslan, 2002: 144). Geçmişte piyasaya yönelik kapsamlı yasal düzenlemelerin hayata geçirilmemiş olması ve iş hukuku açısından gerekli önlemlerin alınmaması bu durumun açık bir göstergesidir. Günümüzde ise çevirmenlerin toplumsal konumlarının değişmesi, bilimsel araştırmalara inceleme konusu olmaları dışında üniversitelerde çevirmenlik eğitiminin yaygınlaşmış olması ve yasal düzenlemelerin çıkarılması adına örgütlenmelerin artmış olmasıyla ilişkilendirilebilir. Bunun yanında, çevirmen isimlerinin öne çıkarılarak aynı esere ilişkin farklı çevirilerinin okurlara sunuluyor olması ve çeşitli yarışma ve ödüllerle nitelikli çevirilerin desteklenmesi kayda değerdir. Türkiye'de çevirmen üzerine söylemleri artsüremli bir gelişim içinde inceleyen Tahir Gürçağlar da "çevirmenlerin toplumsal konumunda bir dönüşüm olduğundan” (Tahir Gürçağlar, 2015: 114) söz eder ve bilhassa "son yıllarda çevirmenlerin söylem üretimine katılmaları ve kendi düşüncelerini söyleme aktarmalarıyla bazı değişiklikler” (Tahir Gürçağlar, 2015: 86) gözlemlendiğini saptamaktadır. Günümüzde kaleme alınan edebî eserlerde de çevirmen figürlerine yer verildiği ve meslekleriyle ilgili kurgusal düzlemde bilgi verildiği görülmektedir. Klasik şablonları tekrardan yapılandırma ve tersyüz etme potansiyeline sahip olan edebî metinlerde, çevirmen figürlerinin kahraman olarak portresinin nasıl ele alındığ bu anlamda çok önemlidir.

İncelediğimiz Kan ve Gül romanı, çevirmenlik mesleğini sürdürmüş olan bir yazarın kaleminden çıkmış olması, ana karakterin mütercim-tercümanlık mezunu bir çevirmen olması, geçen yıllarla birlikte "tam anlamıyla görünür olma” yolunda önemli değişimlerin yaşandığının somut kanıtıdır. Tüm romanlarının temel meselesinin “özgürlük” (Menteş, 2017) olduğunu belirten Canıgüz, Kan ve Gül romanı ile sadece polisiye türüne değil, aynı zamanda 
çevirmen figürünün kurgusal olarak inşa edilmesine de yeni bir soluk getirmektedir. Çünkü Canıgüz, Türk edebiyatının klasikleri arasında yer alan Sabahattin Ali'nin Kürk Mantolu Madonna eserinde olduğu gibi "mızmız", "hastalıklı", "hımbıl”, "zavallı" ve "sessiz, sedası" (Ali, 2010) gibi sıfatlarla betimlenen Raif Efendi örneğinde olduğu gibi kurgusal düzlemde marjinal olarak konumlandırılan ve silik karakterler olarak resmedilen çevirmen figürünü değişime uğratmakta, kurgusal boyutta tekrar inşa etmekte ve bir kahraman olarak tasarlamaktadır. Çevirmenin, hapishaneye dönüşmüş hayatından özgürlüğe doğru gerçekleştirdiği yolculuğunu izleyen okur, onun başkahraman olarak ne kadar güçlendiğine tanık olur.

Son olarak, çevirmen kültürler ötesi dünyada modern varoluşun bir sembolü haline gelmiştir (Lebedewa, 2013: 269) ve yapılan çalışmalar, bu sembolik değerin dünya edebiyatına da yansıdığını göstermektedir. Yazın geleneğinde izlenen bu değişimin sadece Kan ve Gül eserinde değil Türk edebiyatının başka eserlerinde de yankı bulup bulmadığına bakmak adına günümüz kurmaca eserlerin analiz edilmesi elzemdir. Batı literatürüne damgasını vurmuş olan kültürel dönemeç paradigması perspektifiyle Türk edebiyatına yönelik örnek bir analiz modeli sunduğumuz ve kültürbilimsel yaklaşımın uygulanabilirliğini gösterdiğimiz bu inceleme ile modern varoluşun bir sembolü haline gelen çevirmen figürü üzerinden modern insan ve modern insanın kendini konumlandırması ile ilgili önemli veriler elde ettiğimizi ve bu çerçevede bireyi anlama yönünde katkı sağladığımızı düşünüyoruz. İleride bu alanda yapılacak çalışmaların konuya daha fazla ışık tutacağı şüphesizdir.

\section{Notlar}

1 Bu makale Ege Üniversitesi tarafından desteklenen SHD-2020-22159 kodlu "Kurmaca Anlatıda Çevirmen Figürü ve Çevirmenlik Mesleği’” başlıklı BAP-Projesi kapsamında hazırlanmıştır.

2 Farklı perspektiflerden inceleyen örnek çalışmalar için bkz. Arı, 2021, Çoban, 2019; Ece, 2015; Tahir Gürçağlar, 2019a; Okyayuz/ Kaya, 2019; Öncü, 2018; Vardar, 2019 ve Yılmaz Gümüş, 2018.

3 Konuyla ilgili ayrıntılı bilgi için bkz. Bachmann-Medick, 2007.

4 Çevirmenin çevirideki görünürlüğünü irdeleyen Venuti'den farklı olarak burada görünürlükle çevirmenin toplum içindeki önem ve statüsü kastedilmektedir (Venuti, 1995).

5 Hermeneutik kavramı batı dillerinde metinler üzerinde yapılan dolaylı yorum anlamında kullanılır ve metin üzerinden olan tüm yorumbilimsel yaklaşımları temsil eder (Tosun/ Akın 2018: 9-10). Geçirdiği evreleri de göz önünde bulundurarak hermeneutiği edebiyat bağlamında ele alan Toprak (2016)'ın çalışmasında konuyla ilgili kapsamlı bir kaynakça da sunulmaktadır. Türkçeye çevirisinde yorumsama, yorum sanatı, yorumbilim, yorumcu yaklaşım, yorum bilgisi, yorumsal düşünme, hermenötik ve hermeneutik gibi karşılıklar bulmak mümkündür.

6 Burada bahsedilen kurmaca dünyanın çevirmen figürlerine örnek Halit Ziya Uşaklıgil’in Mai ve Siyah eserindeki pasif kişiliği ile göze çarpan başkahraman Ahmet Cemil veya Sabahattin Ali’nin Kürk Mantolu Madonna eserinde karşımıza çıkan Raif Efendi gösterilebilir. Türk romanında çeviri ve çevirmen söylemlerini inceleyen benzer eserler için bkz. Erkul Yağc1, 2015.

7 Anlatım kuramı bağlamında kullanılan bu kavramlarla ilgili ayrıntılı olarak bkz. Scheffel/ Martinez, $2020: 88$.

8 Alanla ilgili 2011 yllında First International Conference on Fictional Translators in Literature and Film ad altında önemli bir konferans düzenlenmiş ve sunulan bildiriler Kaindl/ Spitzl'in Transfiction. Research into the Realities of Translation fiction isimli eserde yayımlanmıştır Kaindl/ Spitzl, 2014). Konuyla ilgili çalışmalar özellikle sonraki yıllarda hız kazanmıştır.

9 Kaindl'ın analiz yöntemine ilişkin başka bir örnek için bkz. Tanış Polat, 2019: 49. 
10 Kurgusal eserler üzerinden farklı türleri ve algılanış biçimleri konusunda ayrıntılı bilgi verdiği araştırmasında, Kocabıyık (baskıda), zaman yolculuğu ile ilgili “bir dönüşümün sembolü”, “yeninin yaratımı”, “[olanları] değiştirebilme arzusu" gibi kavramlar kullanır.

11 Çeviribilimsel açıdan da yazın çevirisi diğer çeviri türlerine göre farklı konumlanmaktadır. Örneğin Faruk Yücel, yazınsal metinlerin çevirisinin yoruma dayalı bir nitelik taşıması nedeniyle metin türleri arasında "en tartışmalı" ve "en zorlu alan” olduğunu savunmaktadır, çünkü "doğrudan bilgi aktarma işlevi olmayan yazınsal metinlerde benzerlik ya da yineleme değil, oluşturulan metnin farklılığı ve öznelliği ön plandadır" (Yücel, 2013: 19-21).

12 Bir cinayetin veya katilin hikâyesini anlatan polisiye türünün en temel özelliği cinayetin bir detektif tarafından aydınlatılması olarak görülmektedir (Plummer, 2007: 404).

13 Bilhassa postkolonyal kuram bağlamında öne çıkan bu kavram ile ilgili ayrıntılı olarak bkz. Bhabha, 1994: 55-56.

14 Burada yer alan çeviri ve sonraki alıntıların çevirisi tarafımıza aittir.

\section{Kaynakça}

Ali, S. (2010). Kürk mantolu Madonna. Yapı Kredi.

Andres, D. (2009). Dolmetscher in fiktionalen Werken - von Verirrung, Verwirrung und Verführung. Das Wort Germanistisches Jahrbuch Russland. 2009, ss. 23-26.

Aslan N. (2002). Kültür aktarımının adsız kahramanları: Çevirmenler (Bir kültür, bir yazar ve onun üç çevirmeni). Ege Alman Dili ve Edebiyatı Araştırmaları Dergisi. Edebi Çeviri ve Kültür Transferi Özel Sayısı. 2002(4), ss. 143-151.

Bachmann-Medick, D. (1999). $1+1=3$ ? Interkulturelle beziehungen als 'dritter raum'. Weimarer Beiträge. Zeitschrift für Literaturwissenschaft, Ästhetik und Kulturwissenschaften 45(4), ss. 518531.

Bachmann-Medick, D. (2007). Cultural turns. Neuorientierungen in den Kulturwissenschaften. Rowohlt.

Bahadır, Ş. (2004). Üçüncü kültürün ortasındayım. Varlık. 2004 Ocak (1156), ss. 24-29.

Bassnett, S. (2003). Translation as re-membering. (Caldicott, E., Fuchs, A. Ed.) Cultural memory: Essays on european literature and history içinde. ss. 293-309. P. Lang.

Bhabha, H. K. (1994). The location of culture. Routledge.

Bourdieu, P. (1984). Distinction: A social critique of the judgement of taste (R. Nice, Çev.) Harvard University.

Canıgüz, A. (2019). Kan ve gül. Bir kara dejavu (6. basım) April.

Çoban, F. (2019). Çevirmen öyküleri: Bir özbetimleme çalışması. Gece Akademi.

Ece, A. (2016). Çevirmenin yazar ve kahraman olarak portresi. Çeviribilim.

Erkul Yağcı, A. S. (2015) Discourses on translation and translators in Turkish fiction. Yayımlanmamış yüksek lisans tezi. Dokuz Eylül Üniversitesi.

Geertz, C. (1993). Thick description: Toward an interpretive theory of culture. Geertz, C. The interpretation of cultures: Selected essays ss. 3-32. Fontana.

Greenblatt, S. (1988). Shakespearean negotiations. The circulation of social energy in renaissance England. University of California.

Kaindl, K. (2008). Zwischen fiktion und wirklichkeit: TranslatorInnen im spannungsfeld von wissenschaft, literatur und sozialer realität. (Schippel, L. Ed.) Translationskultur-ein innovatives und produktives Konzept içinde. ss.307-333. Frank \& Timme. 
Kaindl, K. (2010). Von Fährmännern, Drachen und Killern. Zur fiktionalen identität von translator innen und ihrer theoretischen fundierung. (Sommerfeld, B. Ed.) Identitätskonstruktionen in fiktionalen und nicht-fiktionalen texten. Übersetzung und rezeption içinde ss. 53-72. Peter Lang.

Kaindl, K. ve Spitzl, K. (2014). transfiction. Research into the realities of translation fiction. Benjamins.

Kocabıyık, O. (basımda). Bilimkurgu sinema ve edebiyatında bir geçiş ritüeli olarak zaman yolculuğu.

Lebedewa, J. (2013). Tabu und übersetzung. (Lehmann-Carli, G. Ed.) Empathie und Tabu(bruch) in Kultur, Literatur und Medizin içinde ss. 269-277. Frank \& Timme.

Martinez, M. ve Scheffel, M. (2007). Einführung in die erzähltheorie (7. basım). C.H. Beck.

Neumann, B. (2006). Kulturelles wissen und literatur (Gymnich, M., Neumann, B., Nünning, A. Ed.) Kulturelles wissen und intertextualität. Theoriekonzeptionen und Fallstudien zur Kontextualisierung von Literatur içinde ss. 29-52. Wissenschaftlicher Verlag.

Plummer, P. (2007). Kriminalroman. (Burdorf, D., Fasbender, C., Moenninghoff, B. Ed.) Metzler Lexikon Literatur. Begriffe und Definitionen içinde (3. basım, ss. 404-405). Metzler.

Scheffel, M. ve Martinez, M. (2020). Anlatım teorisine giriş (A. Ünal, Çev.) Runik.

Schirmer, A. (2014). Keine Kuh auf der Weide - Der "Thrill” des Übersetzens in einer Erzählung der Übersetzerin Park Chang Soon. (Kelletat, A. F., Tashinskiy, A. Ed.) Übersetzer als Entdecker. Ihr Leben und Werk als Gegenstand translationswissenschafticher und literaturgeschichtlicher Forschung ss. 161-184. Frank \& Timme.

Tahir Gürçağlar, Ş. (2015). Kapılar. Çeviri tarihine yaklaşımlar (2. basım). Scala.

Tahir Gürçağlar, Ş. (Ed.) (2019a). Türkiye'de kadın çevirmenler. Kelimelerin kıyısında. İthaki.

Tahir Gürçağlar, Ş. (2019b). Giriş (T. Gürçağlar, Ş. Ed.) Türkiye'de kadın çevirmenler. Kelimelerin kıyısında içinde ss. 9-25. İthaki.

Tanış Polat, N. (2019). Heroische konzeptualisierung der translatorin-Figur in dem Film Arrival von Denis Villeneuve. (Ozil, Ş., Hofmann, M., Laut, J. P., Dayığlu-Yücel, Y., Zierau, C. Ed.) Übersetzung als Kulturaustausch. Türkisch-Deutsche Studien Jahrbuch 2018 içinde. ss. 45-59. Universitätsverlag.

Toprak, Metin (2016). Hermeneutik ve edebiyat. Dergâh.

Tosun, M. ve Akın, A. (2018). Yorumbilim. Sosyal bilimler için hermeneutik. Değişim.

Uşaklıgil, H. Z. (2018). Mai ve siyah. Can.

Vardar, S. (2019). Bu kulaklar neler duydu- Türkiye'de konferans çevirmenliğinin 50. yıl. h2o Kitap.

Venuti, L. (1995). The translator's invisibility. A history of translation. Routledge.

Yücel, F. (2013). Ötekinin gözünden Orhan Pamuk. “Beyaz Kale’yi çevirmek”. Aylak Adam.

\section{Elektronik kaynaklar}

Arı, S. (2021). Toplumsal yaşamda çevirmen algısı ve edebiyat metinlerine yansıması: Tercüman Raif Efendi. Çeviribilim ve Uygulamaları Dergisi. 2021 Bahar (30), 1-17. http://10.37599/ceviri.880710

Çeşit, Ö. ve Kozanoğlu, A. (2017). Eksik olan. Bir kara dejavu. https://www.youtube.com/ watch? $\mathrm{v}=$ erIHtf3z_yU

Harman, Ö. F. (1991). Aziz. Türkiye diyanet vakfi Íslam ansiklopedisi. 4(332). https://www.islamansiklopedisi.org.tr/aziz--hristiyanlik 
Menteş, M. ve Canıgüz, A. (2017). Kan ve gül. Kahkaha ve polisiye. Hürriyet Kitap Sanat. https://www. hurriyet.com.tr/kitap-sanat/kan-ve-gul-kahkaha-ve-polisiye-40419324

Okyayuz, A. Ş. ve Kaya, M. (2019). Karikatürlerde çevirmen ve çeviri. Çeviribilim ve Uygulamaları Dergisi. 27, 152-176. https://doi.org/10.37599/ceviri.570416

Öncü, M. T. (2018). Türkçe çevirmenler sözlüğ̈̈. https://translex.ege.edu.tr/tr-6067/turkce_cevirmenler_sozlugu.html

Pekdoğan, D. M. (2017). Yüzleşme olmadan ilerleme olamıyor. https://www.artfulliving.com.tr/edebiyat/yuzlesme-olmadan-ilerleme-olamiyor-i 11880

Y. Gümüş, V. (2018). 21. yüzyıl Türk romanında çevirmen karakterler: Satır aralarında çevirmenlik mesleğine dair ipuçları peşinde. Journal of Turkish Studies. Language/ Literature. 13(12), 591-611. https://doi.org/10.7827/turkishstudies.13506

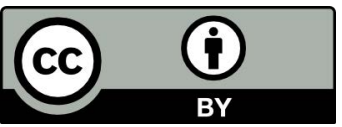

Bu eser Creative Commons Atıf 4.0 Uluslararası Lisansı ile lisanslanmıştır. (This work is licensed under a Creative Commons Attribution 4.0 International License). 